\title{
Dietary Restriction Does Not Adversely Affect Bone Geometry and Mechanics in Rapidly Growing Male Wistar Rats
}

\author{
JENNIFER LAMBERT, JEREMY M. LAMOTHE, RONALD F. ZERNICKE, ROLAND N. AUER, AND \\ RAYLENE A. REIMER
}

Faculty of Kinesiology [J.L., J.M.L., R.F.Z., R.A.R.], McCaig Centre for Joint Injury and Arthritis

Research [J.M.L., R.F.Z.], Department of Pathology and Laboratory Medicine [R.N.A.], Department of

Biochemistry and Molecular Biology [R.A.R.], University of Calgary, Calgary, Alberta, Canada, T2N 1N4

ABSTRACT

\begin{abstract}
The present study assessed the effects of dietary restriction on tibial and vertebral mechanical and geometrical properties in 2-mo-old male Wistar rats. Two-month-old male Wistar rats were randomized to the ad libitum $(n=8)$ or the $35 \%$ dietrestricted (DR) feeding group $(n=9)$ for 5 mo. Tibiae and $\mathrm{L}_{6}$ vertebrae were dissected out for microcomputed tomography $(\mu \mathrm{CT})$ scanning and subsequently fractured in biomechanical testing to determine geometrical and mechanical properties. The DR group had significantly lower mean tibial length, mass, area, and cross-sectional moment of inertia, as well as vertebral energy to maximal load. After adjustment for body mass, however, DR tibial mean maximal load and stiffness, and DR vertebral area, height, volume, and maximal load were significantly greater, relative to ad libitum means. No significant differences were found between the DR and ad libitum mineral ash fractions. Because the material properties of the tibiae between the two groups were not significantly different, presumably the material
\end{abstract}

integrity of the bones was not adversely affected as a consequence of DR. The similar material characteristics were consistent with mineral ash fractions that were not different between the two groups. Vertebral maximal load and stiffness were not significant between the DR and ad libitum animals. Importantly, we show that a level of dietary restriction (35\%) that is less severe than many studies $(40 \%)$, and without micronutrient compensation does not adversely affect tibial and vertebral mechanical properties in young growing male rats when normalized for body mass. (Pediatr Res 57: 227-231, 2005)

BMD, bone mineral density

\section{Abbreviations}

DR, diet-restricted

$\mathbf{L}_{\mathbf{6}}, 6^{\text {th }}$ lumbar

$\boldsymbol{\mu C T}$, microcomputed tomography
DR has emerged as an important avenue of investigation in the area of aging — specifically the prevention of aging. DR can increase both mean and maximal life span in a variety of animals, including rodents and primates (1). Whereas some studies of DR have focused singularly on reducing total calories, without compensation for micronutrient intake (2-4), others have maintained adequate and equal vitamin and mineral status for both DR and ad libitum animals $(5,6)$. Studyto-study variations exist in method and degree of restriction,

Received January 30, 2004; accepted July 8, 2004.

Correspondance: Raylene Reimer, Ph.D., RD, Faculty of Kinesiology, University of Calgary, 2500 University Drive NW, Calgary, AB T2N 1N4, Canada; e-mail: reimer@ucalgary.ca

Supported in part by Natural Sciences and Engineering Research Council, Canadian Institutes of Health Research, Alberta Heritage Foundation for Medical Research, and the Margaret Gunn Endowment for Animal Research. J.L. received funding as a MarkinFlanagan Scholar at the University of Calgary.

DOI: 10.1203/01.PDR.0000148715.61869.4E period of dietary restriction, and the age at onset of restriction, and contribute to the lack of consensus on the effects of dietary restriction on bone adaptation.

Talbott et al. (7) used "younger" (3-mo-old) and "older" (10-mo-old) female Sprague-Dawley rats, matched for body mass and assigned to one of four diet groups representing two levels of energy (referred to as "caloric") intake and two levels of calcium intake. All rats had the same baseline diet (protein, fat, fiber, vitamins, and other minerals), but differed in caloric intake (normal versus $40 \%$ restriction) by reduced carbohydrate content or levels of calcium intake (normal $=78 \mathrm{mg} / \mathrm{d}$ and low $=15 \mathrm{mg} / \mathrm{d}$ ). Rats were, therefore, restricted in calcium only, calories only, or calcium and calories, for a period of 9 wk. Dietary restriction of calcium or energy resulted in an elevated rate of bone turnover in both younger and older rats. Dietary restriction of energy alone had no significant influence on final BMD in younger rats. In older rats, however, final BMD was negatively influenced by DR, suggesting that although calcium or DR increased bone turnover in a similar 
fashion in both younger and older rats there were still agerelated differences of the influence of DR on BMD.

In a subsequent study, Talbott et al. (8) looked at the interaction of age and DR in relation to bone biomechanical properties. "Mature" (5-mo-old) and "aged" (12-mo-old) female Sprague-Dawley rats, approximately equivalent to 20 and 50 human years, respectively, were fed ad libitum or at $40 \%$ restriction for $9 \mathrm{wk}$. Both age groups experienced a 15\% loss of body weight and decreased femoral bone density (32-35\%). Despite small reductions in tibial and humeral density in both groups, biomechanical properties were reduced in aged but not mature rats. Clearly, the age at onset of DR in rats carried important implications for bone adaptation.

Additional support for an age-sensitive component of changes in bone metabolism comes from work by LaMothe $e t$ al. (5), who compared DR and ad libitum male Fischer $344 \mathrm{X}$ Brown-Norway F1-hybrid rats. Rats were studied at ages representing "young adult" ( 8 mo old), "late middle aged" (28 mo old), and "senescence" (36 mo old). A group of rats 28 mo old was calorically restricted at $40 \%$ since 14 wk of age. Relative to age-matched ad libitum rats, the 28-mo-old DR rats had significantly shorter tibial lengths, and reduced total bone cross-sectional area, cortical shell area, mineral ash fraction, cross-sectional moment of inertia, load at proportional limit, maximal load, stiffness, and flexural rigidity. Relative to agematched ad libitum rats, DR rats also had significantly shorter $\mathrm{L}_{6}$ height and lower loads at the proportional limit and maximum. They concluded that DR adversely affected bone geometry and mechanics in aged male F344BN rats.

Body weight is recognized as a consistent predictor of BMD with body weight loss resulting in reductions in bone mass $(6,7,9-13)$. Although Talbott et al. (7) failed to detect a significant reduction in BMD in young $(3 \mathrm{mo}$ ) dietary-restricted rats, the effects on skeletal biomechanical and geometrical properties are not known. Given the significant effects of DR on age-related processes $(14,15)$ and the questions arising regarding the age at which restriction is best initiated, it is important to address what effects DR-induced reductions in growth and accrual of total body mass have on bone strength in young rats.

A variety of levels of DR have been investigated but restricting food intake to $50-70 \%$ of that eaten by ad libitum rats is most commonly associated with increases in longevity and delays in age-associated physiologic deterioration (16-20). As such, the present study sought to determine the effect of DR (65\% of ad libitum) on mechanical and structural properties of bone in young male Wistar rats. Importantly, this study examined how a period of DR longer than those of Talbott et al. (8) but shorter than those of LaMothe et al. (5) affected skeletal properties of young male Wistar rats. A restriction of 35\% without nutritional supplementation was used, and we hypothesized that the growth and accrual of body weight in young rats would counterbalance the DR-related, deleterious effects in tibial and vertebral geometrical and mechanical properties seen in aged rats.

\section{MATERIALS AND METHODS}

Animals. Seventeen 2-mo-old male Wistar rats were randomly assigned to one of two groups: one group $(n=8)$ was fed standard rat chow ad libitum
(Prolab RMH 2500, PMI Nutrition International Brentwood MO; $24 \%$ protein, $6 \%$ fat, $5.3 \%$ fiber, $6.9 \%$ ash, $0.95 \%$ calcium, $0.69 \%$ phosphorus), whereas the other group $(n=9)$ received $65 \%$ of the amount of food consumed by their respective ad libitum-fed controls on the previous day (i.e. $35 \%$ DR). Both were housed in standard rat cages with a 12:12 light-dark cycle. On the day of sacrifice, rats were anesthetized with halothane and killed by cervical dislocation. Carcasses were frozen $\left(-80^{\circ} \mathrm{C}\right)$ until the time of dissection. After thawing and on the day of dissection, tibiae and the $\mathrm{L}_{6}$ vertebrae were dissected and cleaned of nonosseous tissue for each rat. Bones were individually wrapped in saline-soaked gauze, sealed hermetically in plastic bags, and frozen until $\mu \mathrm{CT}$ scanning. On the day of scanning, bones were thawed in roomtemperature PBS. Freezing and thawing do not have adverse effects on rat bone mechanical properties $(21,22)$. All procedures were ethically approved by the University of Calgary Animal Care Committee and conformed to procedures set forth for the Care and Use of Laboratory Animals.

Tibial bone geometry. Randomly, either the right or left tibia from each rat was imaged using $\mu \mathrm{CT}$. Once thawed, tibiae were scanned (Skyscan 1073, SkyScan, Aartselaar, Belgium) at a magnification of $14.07 \times$ (resolution of $19.73 \mu \mathrm{m})$. Scanning generated a series of planar transverse grayscale bitmapped images. After scanning, the bones were again wrapped in salinesoaked gauze and refrozen $\left(-20^{\circ} \mathrm{C}\right)$ until biomechanical testing. Bone geometries were determined by inputting the bitmapped images into custom software (Matlab, Natick, MA), which thresholded images and calculated geometric parameters such as total cross-sectional area, distances from centroid to the desired edge of the cross-section, and cross-sectional moment of inertia.

$L_{6}$ bone geometry. $\mathrm{L}_{6}$ were thawed in room temperature (RT) PBS. Transverse processes were removed with dissection scissors, and the neural spine was removed with a diamond wafer saw (Buehler Isomet, Lake Bluff, IL). Vertebral height was measured with calipers (Model 599-578-1, Brown and Sharpe, Irvine, CA). $\mathrm{L}_{6}$ were subsequently scanned with $\mu \mathrm{CT}$ (Skyscan 1073 ) at a magnification of $30 \times$ (resolution of $12.73 \mu \mathrm{m}$ ). Bitmapped images were generated, and the vertebral centrum was prepared for biomechanical testing. Caudal and rostral surfaces were cut to clean them of intervertebral discs and to ensure parallel surfaces for axial crush testing. After processing, $\mathrm{L}_{6}$ length was measured and then re-wrapped in saline-soaked gauze and frozen $\left(-20^{\circ} \mathrm{C}\right)$ until biomechanical testing. Bone geometries were determined by inputting the bitmapped images into custom software (Matlab), which thresholded images and calculated geometric parameters such as total crosssectional area, cortical bone area, and trabecular area.

Tibial biomechanical testing. Tibiae were thawed in RT saline solution for at least $1 \mathrm{~h}$. Tibial length was measured, and the midshaft marked. For testing, a round-surfaced cross-head probe of a servocontrolled electromechanical testing system (Model 1122, Instron Corp., Canton, MA) contacted the medial tibial surface at the longitudinal midpoint and applied a preload of $1 \mathrm{~N}$. Tibiae were fractured in three point-bending (loading span of $13.3 \mathrm{~mm}$ ) at 25.4 $\mathrm{mm} / \mathrm{min}$ (5). Testing order was stratified between groups to eliminate any testing-order effects. Load-deformation curves were generated (RC Computerscope A/D Board, RC Electronics, Santa Barbara, CA). From these, the load at proportional limit, maximal load, and stiffness were calculated. Stiffness was defined as the linear region of the load-deformation curve. Proportional limit was the point where the linear region of the extended load-deformation curve deviated by $>5 \%$ from the experimental curve [percentage difference $=$ (predicted load value - experimental load value) $\cdot 100 \%$ /experimental load value). Among the properties calculated were stress and strain at the proportional limit and maximal load, and flexural rigidity (22a).

$L_{6}$ biomechanical testing. $\mathrm{L}_{6}$ centra were thawed in RT saline for at least $1 \mathrm{~h}$. The caudal surface of the centrum was placed on a stainless steel plate lightly coated with mineral oil to facilitate unconstrained compression. The flat-surfaced crosshead probe of the testing system was also coated with mineral oil and contacted the rostral surface of the centrum with a preload of $5 \mathrm{~N}$. The centrum was cycled with a load from 5 to $10 \mathrm{~N}, 20$ times at $0.001 \% / \mathrm{s}$ to obviate the viscoelastic creep of trabecular bone (23) and was stopped at a preload of $10 \mathrm{~N} . \mathrm{L}_{6}$ were then compressed at a fast strain rate (50\%/s) (5). Structural properties were calculated (e.g. load at proportional limit, maximal load, and stiffness), as well as $\mathrm{L}_{6}$ material stress and strain.

Ash analysis. Biomechanically tested tibiae and vertebrae were defatted in acetone for $7 \mathrm{~d}$, dehydrated at $100^{\circ} \mathrm{C}$ (Thermolyne F62700, Barnstead International, Dubuque, IA) for $48 \mathrm{~h}$ in ceramic crucibles. Dehydrated samples were 
measured $( \pm 0.01 \mathrm{mg}$; Mettler AE 163, Mettler-Toledo, Inc., Columbus, OH) to determine dry bone mass. The samples were then incinerated at $600^{\circ} \mathrm{C}$ for $48 \mathrm{~h}$, and the ash was measured (24). The ash mass divided by the dry mass was determined as the mineral ash fraction.

Statistics. Means and standard deviations were calculated for all variables. Means between the ad libitum and DR groups were compared with a nonparametric two independent samples test (Mann-Whitney $U$ test; SPSS version 11.0, SPSS Inc., Chicago, IL). A significance level of $p \leq 0.05$ was used for all statistical tests.

\section{RESULTS}

Body mass. Final body mass was significantly lower in the DR group by almost $30 \%$ (Fig. 1), relative to ad libitum mass. Growth or increase in body mass over the 5-mo study period was $>260 \%$ in ad libitum rats and $>190 \%$ in DR rats, with DR rats achieving approximately $70 \%$ of the final body mass of the ad libitum rats. Bone structural properties were analyzed before and after adjustment for body mass. Bone mineral density and bone size are related to total body mass, and bone mineral density influences bone strength (25). Therefore, structural properties were reported without and with adjustment for body mass (26). Correction for body mass was achieved by dividing the geometrical or structural property of interest by body mass (26).

Tibial geometrics and mechanics. Tibial geometrical parameters, including tibial mass, length, area, and crosssectional moment of inertia were significantly lower in the DR group (Table 1). DR tibial load and stress at proportional limit were reduced about $\sim 20 \%$ but that was not significantly different from ad libitum rats. When adjusted (normalized) to total body mass, however, DR tibial values (e.g. maximal load, stiffness, flexural rigidity, mass, length, and area) were significantly greater than for the ad libitum rats (Table 2). The tibial mineral ash fraction was not different between the two groups.

$L_{6}$ geometry and mechanics. No significant differences were found between the two groups except for energy to maximal load, which was significantly $(\sim 20 \%)$ lower in the DR group (Table 3). Although DR stiffness and strain at the proportional limit were reduced by $20-25 \%$ when compared with the $a d$ libitum rats, those differences were not statistically significant

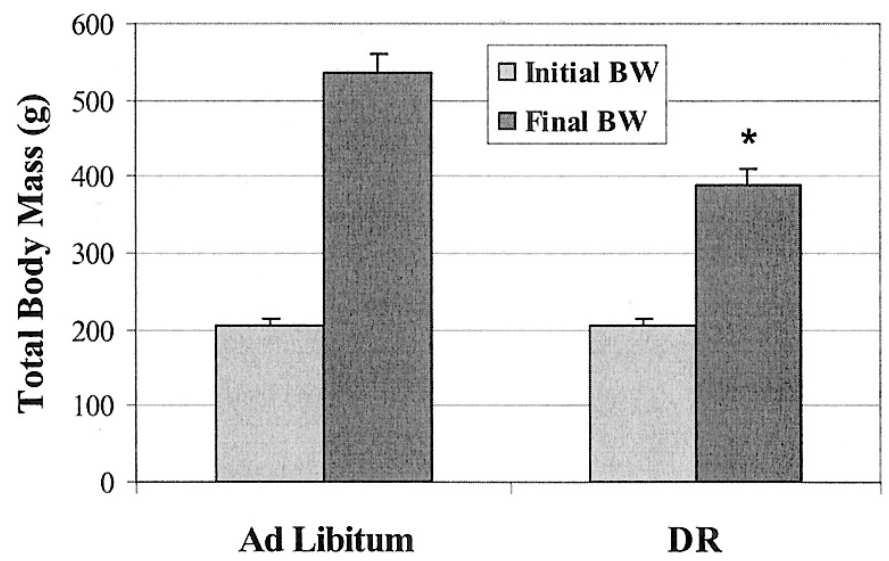

Figure 1. Total body mass of ad libitum-fed and diet-restricted male Wistar rats. Values are presented for the body mass at the beginning of the experimental period and after 5 mo of DR. *Significantly different from final body weight of ad libitum rats, $p<0.05(n=8-9)$.
Table 1. Tibial geometry and mechanics

\begin{tabular}{lcc}
\hline & $\begin{array}{c}\text { Ad libitum } \\
(n=8)\end{array}$ & $\begin{array}{c}\text { DR } \\
(n=9)\end{array}$ \\
\hline Geometrical & & \\
Tibial length (mm) & $49.2 \pm 9.0$ & $44.3 \pm 1.0^{* \dagger}$ \\
Tibial mass $(\mathrm{g})$ & $1.4 \pm 0.1$ & $1.2 \pm 0.1^{* \dagger}$ \\
Total cross-sectional area $\left(\mathrm{mm}^{2}\right)$ & $5.6 \pm 0.5$ & $4.8 \pm 0.3^{* \dagger}$ \\
Cross-sectional moment of inertia $\left(\mathrm{mm}^{4}\right)$ & $3.7 \pm 0.8$ & $2.7 \pm 0.2^{*}$ \\
Structural & & \\
Maximal load (N) & $166.7 \pm 30.3$ & $143.0 \pm 27.6 \dagger$ \\
Load at proportional limit (N) & $155.5 \pm 32.7$ & $126.3 \pm 54.4$ \\
Stiffness (kN/mm) & $378.0 \pm 67.4$ & $359.0 \pm 20.9 \dagger$ \\
Displacement at maximal load $(\mathrm{mm})$ & $0.5 \pm 0.1$ & $0.5 \pm 0.1$ \\
Displacement at proportional limit $(\mathrm{mm})$ & $0.5 \pm 0.1$ & $0.4 \pm 0.2 \dagger$ \\
Energy to proportional limit $(\mathrm{kN} \cdot \mathrm{mm})$ & $17.2 \pm 5.0$ & $16.0 \pm 7.6$ \\
Energy to maximal load $(\mathrm{kN} \cdot \mathrm{mm})$ & $22.4 \pm 11.2$ & $23.6 \pm 9.2$ \\
Material & & \\
Stress at maximal load $(\mathrm{MPa})$ & $175.8 \pm 21.0$ & $191.3 \pm 37.6$ \\
Stress at proportional limit $(\mathrm{MPa})$ & $163.0 \pm 19.9$ & $190.5 \pm 38.9$ \\
Strain at maximal load $(\%)$ & $41.0 \pm 9.0$ & $36.0 \pm 10.0$ \\
Strain at proportional limit $(\%)$ & $36.0 \pm 5.5$ & $30.0 \pm 1.2$ \\
Mineral ash fraction $(\%)$ & $73.0 \pm 0.40$ & $73.4 \pm 0.39$ \\
Flexural rigidity $\left(\mathrm{kN} \cdot \mathrm{mm}{ }^{2}\right)$ & $18.5 \pm 3.3$ & $17.6 \pm 1.0 \dagger$ \\
\hline
\end{tabular}

Values are mean $\pm \mathrm{SD}$. $*$ Significant difference, $p<0.05$. $\dagger$ Significant when corrected for body mass $(p<0.05)$, values presented in Table 2 .

Table 2. Body-mass adjusted tibial geometry and mechanics

\begin{tabular}{lcc}
\hline & $\begin{array}{c}\text { Ad libitum } \\
(n=8)\end{array}$ & $\begin{array}{c}\text { DR } \\
(n=9)\end{array}$ \\
\hline Geometrical & & \\
Tibial length $(\mu \mathrm{m} / \mathrm{g})$ & $92.0 \pm 18.0$ & $110.0 \pm 5.0 \dagger$ \\
Tibial mass $(\mu \mathrm{g} / \mathrm{g})$ & $2.6 \pm 0.2$ & $3.1 \pm 0.1 \dagger$ \\
Tibial length/mass $(\mu \mathrm{m} / \mathrm{g})$ & $67.0 \pm 16.0$ & $94.0 \pm 10.0 \dagger$ \\
Total cross-sectional area $\left(\mu \mathrm{m}^{2} / \mathrm{g}\right)$ & $10.0 \pm 1.0$ & $12.0 \pm 1.0 \dagger$ \\
Cross-sectional moment of inertia $\left(\mu \mathrm{m}^{4} / \mathrm{g}\right)$ & $7.0 \pm 1.0$ & $9.0 \pm 1.0$ \\
Structural & & \\
Maximal load $(\mathrm{N} / \mathrm{g})$ & $0.31 \pm 0.05$ & $0.37 \pm 0.08 \dagger$ \\
Stiffness $(\mathrm{kN} / \mathrm{mm} / \mathrm{g})$ & $0.71 \pm 0.13$ & $0.92 \pm 0.04 \dagger$ \\
Displacement at max load $(\mu \mathrm{m} / \mathrm{g})$ & $1.0 \pm 0.2$ & $1.3 \pm 0.4$ \\
Displacement at $\mathrm{proportional} \mathrm{limit}(\mu \mathrm{m} / \mathrm{g})$ & $0.9 \pm 0.0$ & $1.1 \pm 0.4 \dagger$ \\
Load at proportional limit $(\mathrm{N} / \mathrm{g})$ & $0.29 \pm 0.05$ & $0.33 \pm 0.14$ \\
Energy to proportional limit $(\mathrm{N} \cdot \mathrm{mm} / \mathrm{g})$ & $32.0 \pm 8.7$ & $41.5 \pm 19.7$ \\
Energy to maximal load $(\mathrm{N} \cdot \mathrm{mm} / \mathrm{g})$ & $41.3 \pm 19.4$ & $60.2 \pm 23.5$ \\
Flexural rigidity $\left(\mathrm{N} \cdot \mathrm{mm}^{2} / \mathrm{g}\right)$ & $34.6 \pm 6.6$ & $45.1 \pm 1.8 \dagger$ \\
\hline
\end{tabular}

Values are mean $\pm \mathrm{SD}$. $\dagger$ Significant when corrected for body mass, $p<$ 0.05 .

(Table 3). After adjusting for body mass, the following were significantly greater in the $\mathrm{DR}_{6}$ compared with the ad libitum rats: maximal load, energy to proportional limit, area, height, volume, trabecular area, and cortical area (Table 4). The $\mathrm{L}_{6}$ mineral ash fraction was not different between the two groups.

\section{DISCUSSION}

When normalized for differences in total body mass, the geometrical, structural, and mechanical properties of the tibia and $\mathrm{L}_{6}$ in growing male DR Wistar rats were not adversely affected, compared with ad libitum fed rats. Consistent with previous data $(7,8,27)$, final body mass of DR animals was significantly lower than the ad libitum animals at the end of the study, but growth continued throughout the 5-mo study. After adjusting for body mass, DR produced changes in tibial geometry but did not significantly alter the structural and material 
Table 3. Rat $L_{6}$ vertebral geometry and mechanics

\begin{tabular}{lcc}
\hline & $\begin{array}{c}\text { Ad libitum } \\
(n=8)\end{array}$ & $\begin{array}{c}\text { DR } \\
(n=9)\end{array}$ \\
\hline Geometrical & & \\
$\mathrm{L}_{6}$ cross-sectional area $\left(\mathrm{mm}^{2}\right)$ & $6.3 \pm 0.4$ & $5.8 \pm 0.4 \dagger$ \\
$\mathrm{L}_{6}$ height $(\mathrm{mm})$ & $6.1 \pm 0.5$ & $6.0 \pm 0.7 \dagger$ \\
$\mathrm{L}_{6}$ volume $\left(\mathrm{mm}^{3}\right)$ & $38.2 \pm 4.3$ & $34.7 \pm 4.3 \dagger$ \\
Trabecular area $\left(\mathrm{mm}^{2}\right)$ & $2.0 \pm 0.3$ & $2.1 \pm 0.1 \dagger$ \\
Cortical area $\left(\mathrm{mm}^{2}\right)$ & $3.6 \pm 0.3$ & $3.6 \pm 0.2 \dagger$ \\
Structural & & \\
Maximal load $(\mathrm{N})$ & $461.3 \pm 38.0$ & $396.5 \pm 87.3 \dagger$ \\
Load at proportional limit $(\mathrm{N})$ & $353.5 \pm 70.5$ & $300.0 \pm 125.6$ \\
Stiffness $(\mathrm{kN} / \mathrm{mm})$ & $527.6 \pm 222.4$ & $397.1 \pm 240.6 \dagger$ \\
Displacement at maximal load $(\mathrm{mm})$ & $3.6 \pm 2.8$ & $3.4 \pm 3.1$ \\
Displacement at proportional limit $(\mathrm{mm})$ & $1.1 \pm 0.5$ & $1.3 \pm 1.0$ \\
Energy to proportional limit $(\mathrm{kN} \cdot \mathrm{mm})$ & $40.8 \pm 13.1$ & $45.1 \pm 22.9 \dagger$ \\
Energy to maximal load $(\mathrm{kN} \cdot \mathrm{mm})$ & $22.4 \pm 77.4$ & $12.9 \pm 64.0 *$ \\
Material & & \\
Stress at maximal load $(\mathrm{MPa})$ & $73.5 \pm 6.8$ & $67.7 \pm 13.5$ \\
Stress at proportional limit $(\mathrm{MPa})$ & $56.1 \pm 9.9$ & $51.6 \pm 20.9$ \\
Strain at maximal load $(\%)$ & $60.8 \pm 48.5$ & $56.6 \pm 52.8$ \\
Strain at proportional limit $(\%)$ & $17.2 \pm 8.8$ & $22.5 \pm 18.5$ \\
Mineral ash fraction $(\%)$ & $63.8 \pm 1.5$ & $64.3 \pm 1.5$ \\
\hline
\end{tabular}

Values are mean $\pm \mathrm{SD} . *$ Significant difference, $p<0.05$. $\dagger$ Significant when corrected for body mass $(p<0.05)$, values presented in Table 4 .

Table 4. Body-mass-adjusted $L_{\sigma}$ vertebral geometry and mechanics

\begin{tabular}{lcc}
\hline & $\begin{array}{c}\text { Ad libitum } \\
(n=8)\end{array}$ & $\begin{array}{c}\mathrm{DR} \\
(n=9)\end{array}$ \\
\hline Geometrical & & \\
$\mathrm{L}_{6}$ cross-sectional area $\left(\mu \mathrm{m}^{2} / \mathrm{g}\right)$ & $12.0 \pm 0.7$ & $15.0 \pm 1.4 \dagger$ \\
$\mathrm{L}_{6}$ height $(\mu \mathrm{m} / \mathrm{g})$ & $11.0 \pm 0.8$ & $15.0 \pm 2.3 \dagger$ \\
$\mathrm{L}_{6}$ volume $\left(\mu \mathrm{m}^{3} / \mathrm{g}\right)$ & $71.0 \pm 7.0$ & $89.0 \pm 14.0 \dagger$ \\
Trabecular area $\left(\mu \mathrm{m}^{2} / \mathrm{g}\right)$ & $3.7 \pm 0.6$ & $5.4 \pm 0.4 \dagger$ \\
Cortical area $\left(\mathrm{mm}^{2} / \mathrm{g}\right)$ & $7.0 \pm 0.8$ & $9.2 \pm 1.0 \dagger$ \\
Structural & & \\
Maximal load $(\mathrm{N} / \mathrm{g})$ & $0.87 \pm 0.08$ & $1.03 \pm 0.23 \dagger$ \\
Stiffness $(\mathrm{kN} / \mathrm{mm} / \mathrm{g})$ & $0.85 \pm 0.54$ & $1.03 \pm 0.63 \dagger$ \\
Displacement at maximal load $(\mu \mathrm{m} / \mathrm{g})$ & $6.8 \pm 5.2$ & $8.8 \pm 8.3$ \\
Displacement at proportional limit & $2.0 \pm 1.0$ & $3.4 \pm 2.6$ \\
$(\mu \mathrm{m} / \mathrm{g})$ & & \\
Load at proportional limit $(\mathrm{N} / \mathrm{g})$ & $0.66 \pm 0.14$ & $0.78 \pm 0.33$ \\
Energy to proportional limit $(\mathrm{N} \cdot \mathrm{mm} / \mathrm{g})$ & $76.5 \pm 24.0$ & $116.9 \pm 59.6 \dagger$ \\
Energy to maximal load $(\mathrm{N} \cdot \mathrm{mm} / \mathrm{g})$ & $419.2 \pm 141.7$ & $334.6 \pm 165.3$ \\
\hline
\end{tabular}

Values are mean $\pm \mathrm{SD}$. $\uparrow$ Significant when corrected for body mass, $p<$ 0.05 .

properties compared with the ad libitum group. Indeed, when adjusted for total body mass, some DR tibial structural properties (maximal load and stiffness) were significantly greater than the ad libitum group.

$\mathrm{L}_{6}$ geometry and structural and material properties were not significantly different between the two groups before adjustment for body mass. After adjusting for total body mass, all $\mathrm{L}_{6}$ geometrical values and several structural properties were significantly greater in the DR group, compared with the ad libitum group. The general absence of detrimental effects on bone geometric and mechanical properties in DR rats contrasts with typical findings from several studies with mature or aged rats $(5,7,8)$. The current results support the findings of Talbott et al. (7), in which DR did not adversely affect BMD in young rats. Our results provided evidence that DR at a level of $35 \%$ restriction without micronutrient supplementation in young growing rats did not adversely affect bone geometry or mechanics. This is an important finding given that our understanding of the dose response effects of DR on bone mechanics is limited, including at which level of restriction micronutrient compensation is critical or necessary to maintain optimum bone mechanical properties.

Diverse protocols have been used to assess the impact of DR on bone, including studies restricting energy from $4 \mathrm{wk}$ (28) to 4 mo (28a), matched (5) or not matched $(2,3)$ micronutrient intake, using rats of various ages, sex, and strains $(6,28)$. Our study involved a moderate level of restriction (35\%), longer period of restriction $(5 \mathrm{mo})$, and initiated the restriction period at 2 mo of age in male Wistar rats. Peak bone mass is achieved by approximately $10 \mathrm{mo}$ in rats (29-31), thus, the Wistar rats in the current study were growing throughout the entire study. As several studies demonstrate adverse effects of DR on bone in mature or aged rats $(5,7,8)$, it is possible that an early adaptive response related to growth in the young rats confers protection from the deleterious effects of DR on bone. Our work suggests that despite DR without micronutrient compensation, there were no adverse effects on bone geometry or mechanics in young, growing rats. This protective mechanism requires further investigation.

In the present study, tibiae from DR rats were significantly smaller in length, mass, and area when compared with ad libitum tibiae, which suggested a possible inhibitory effect on bone growth. Stunted bone growth has been demonstrated in several other studies $(5,27)$. When normalized for total body mass, however, DR tibiae length, mass, and area were significantly greater than the ad libitum rats, suggesting that bone growth per unit body mass was not diminished with our DR paradigm.

Independent of body mass, DR did not alter any of the $\mathrm{L}_{6}$ geometry or material properties, and only energy to maximal load was significantly lower in structural properties. Normalizing these properties for body mass resulted in a consistent improvement in all $\mathrm{L}_{6}$ geometries and several structural properties with DR. Our findings were in contrast to the negative effects of DR seen in $\mathrm{L}_{6}$ bone responses in mature and aged rats $(5,8,27)$.

Why normalized geometry and mechanical properties were not adversely affected by DR in our young rats was not entirely clear but may be linked to gains in body mass. Our DR rats continued to gain mass throughout the 5-mo restriction period, although at a significantly lower rate of increase than the $a d$ libitum animals. In contrast to the current rats that were in their rapid growth phase, the majority of studies examining DR in mature or aged rats reported a loss of body mass over the course of DR $(5,7,8,27)$. The effects of adult-onset weight loss on bone structural and material biomechanical properties are not completely understood, but Talbott et al. (8) reported that whereas weight loss due to DR was detrimental to some bone parameters in mature rats, only aged rats had consistent reductions in biomechanical properties. Thus, the effects of DR may interact with the aging process to compromise adaptation with increasing age.

In agreement with the findings of Talbott et al. (7) demonstrating no negative influence of DR on BMD in young rats, 
mineral ash fraction was not significantly different between the two groups in the present study. As the material properties of the tibiae and $\mathrm{L}_{6}$ vertebra between the two groups were not significant in this study, it can be assumed that the material integrity of the bones was not adversely affected by the DR paradigm. Our study used a slightly lower level of DR $(35 \%)$ compared with the $40 \%$ of Talbott et al. (7) and we did not compensate for vitamin and mineral intake. It is noteworthy that studies that have specifically assessed energy restriction versus calcium restriction severely limit the calcium content of the diet. For example, Talbott et al. (7) compared a control diet with $0.9 \%$ calcium phosphate to a $0 \%$ level in the calciumrestricted diet and $0.65 \%$ calcium carbonate control to $0.25 \%$ in the calcium-restricted diet. The reduction in micronutrient intake in our study was much less severe given that the restricted rats still received $65 \%$ of the calcium and mineral intake of the ad libitum fed rats $(0.95 \%$ calcium and $0.69 \%$ phosphorus). Therefore, although there was reduced mineral intake in our restricted rats it was not as severely limiting as that of many studies addressing the effects of mineral restriction. Although these differences in study protocol existed, we were still able to show a positive effect of DR on bone change when normalized to body mass. The most likely protective factor in young rats is likely to be the influence of growth and the endocrine environment associated with it. Future studies will need to include detailed analysis of endocrine factors related to growth and anabolism.

In summary, changes in body mass due to DR accounted for minimal differences in $\mathrm{L}_{6}$ and tibial mechanics. When normalized for total body mass, DR did not adversely affect tibial and $\mathrm{L}_{6}$ mechanics in spite of a $35 \%$ restriction in caloric intake in the young, rapidly growing male Wistar rats. The mechanisms of this effect remain unknown but may involve alterations in the endocrine environment associated with growth. The looming public health crisis related to obesity and an increasingly aged population dictates that we fully understand one of the most effective and powerful interventions known to mitigate age-associated disease, DR. Our work suggests that early initiation of DR at a level of 35\% does not adversely affect bone geometry and mechanics in young, growing rats. In the future, it will be important to fully understand the benefits and risks associated with DR.

\section{REFERENCES}

1. Weindruch R, Sohal RS 1997 Seminars in medicine of the Beth Israel Deaconess Medical Center. Caloric intake and aging. N Engl J Med 337:986-994

2. McCay CM, Crowell MF, Maynard LA 1935 The effect of retarded growth upon the length of life span and upon the ultimate body size. J Nutr 10:63-79

3. McCay CM, Maynard LA, Sperling C, Barnes LL 1939 Retarded growth, life span, ultimate body size and age changes in the albino rat after feeding diets restricted in calories. J Nutr 18:1-13

4. Ferguson VL, Greenberg AR, Bateman TA, Ayers RA, Simske SJ 1999 The effects of age and dietary restriction without nutritional supplementation on whole bone structural properties in C57BL/6J mice. Biomed Sci Instrum 35:85-91

5. LaMothe JM, Hepple RT, Zernicke RF 2003 Selected contribution: Bone adaptation with aging and long-term caloric restriction in Fischer 344 x Brown-Norway F1-hybrid rats. J Appl Physiol 95:1739-1745
6. Lee CJ, Panemangalore M, Wilson K 1986 Effect of dietary energy restriction on bone mineral content of mature rats. Nutr Res 6:51-59

7. Talbott SM, Rothkopf MM, Shapses SA 1998 Dietary restriction of energy and calcium alters bone turnover and density in younger and older female rats. J Nutr 128:640-645

8. Talbott SM, Cifuentes M, Dunn MG, Shapses SA 2001 Energy restriction reduces bone density and biomechanical properties in aged female rats. J Nutr 131:2382-2387

9. Lane MA, Raznik AZ, Tilmont EM, Lanir A, Ball SS, Read V, Ingram DK, Cutler RG, Roth GS 1995 Aging and food restriction alter some indices of bone metabolism in male rhesus monkeys (Macaca mulatta). J Nutr 125:1600-1610

10. Lee CJ, Wang C, Panemangalore M 1993 Effect of continuous or cyclic restriction of energy intake on bone mineral content of oophorohysterectomized rats. Nutr Res 13:563-573

11. Wronski TJ, Schenck PA, Clintron M, Walsh CC 1987 Effect of body weight on osteopenia in ovariectomized rats. Calcif Tissue Int 40:155-159

12. Blain H, Vuillemin A, Guillemin F, Durant R, Hanesse B, de Talance N, Doucet B, Jeandel C 2002 Serum leptin level is a predictor of bone mineral density in postmenopausal women. J Clin Endocrinol Metab 87:1030-1035

13. McGuigan FE, Murray L, Gallagher A, Davey-Smith G, Neville CE, Van't Hof R, Boreham C, Ralston SH 2002 Genetic and environmental determinants of peak bone mass in young men and women. J Bone Miner Res 17:1273-1279

14. Turturro A, Hart RW 1991 Longevity-assurance mechanisms and caloric restriction. Ann N Y Acad Sci 621:363-372

15. Heilbronn LK, Ravussin E 2003 Calorie restriction and aging: review of the literature and implications for studies in humans. Am J Clin Nutr 78:361-369

16. Masoro EJ 2000 Caloric restriction and aging: an update. Exp Gerontol 35:299305

17. Chowdhury P, Rayford PL 2001 Effect of food restriction on plasma cholecystokinin levels and exocrine pancreatic function in rats. Ann Clin Lab Sci 31:376-382

18. Brochmann EJ, Duarte ME, Zaidi HA, Murray SS 2003 Effects of dietary restriction on total body, femoral, and vertebral bone in SENCAR, C57BL/6, and DBA/2 mice. Metabolism 52:1265-1273

19. Diniz YS, Cicogna AC, Padovani CR, Silva MD, Faine LA, Galhardi CM, Rodrigues HG, Novelli EL 2003 Dietary restriction and fibre supplementation: oxidative stress and metabolic shifting for cardiac health. Can J Physiol Pharmacol 81:1042-1048

20. Korczynska J, Stelmanska E, Swierczynski J 2003 Differential effect of long-term food restriction on fatty acid synthase and leptin gene expression in rat white adipose tissue. Horm Metab Res 35:593-597

21. Pelker RR, Friedlaender GE, Markham TC, Panjabi MM, Moen CJ 1984 Effects of freezing and freeze-drying on the biomechanical properties of rat bone. J Orthop Res $1: 405-411$

22. Peng Z, Tuukkanen J, Zhang H, Jamsa T, Vaananen HK 1994 The mechanical strength of bone in different rat models of experimental osteoporosis. Bone 15:523532

22a. Akhter MP, Iwaniec UT, Covey MA, Cullen DM, Kimmel DB, Becker R 2000 Genetic variation in bone density, histomorphometry, and strength in mice. Calcif Tissue Int 67:337-344

23. Linde F, Hvid I 1989 The effect of constraint on the mechanical behavior of trabecular bone specimens. J Biomech 22:485-490

24. Judex S, Zernicke RF 2000 High-impact exercise and growing bone: relation between high strain rates and enhanced bone formation. J Appl Physiol 88:21832191

25. Gatti D, Sartori E, Braga V, Corallo F, Rossini M, Adami S 2001 Radial bending breaking resistance derived by densitometric evaluation predicts femoral neck fracture. Osteoporos Int 12:864-869

26. Zernicke RF, Salem GJ, Barnard RJ, Schramm E 1995 Long-term, high-fat-sucrose diet alters rat femoral neck and vertebral morphology, bone mineral content, and mechanical properties. Bone 16:15-31

27. Banu J, Orhii PB, Okafor MC, Wang L, Kalu DN 2001 Analysis of the effects of growth hormone, exercise and food restriction on cancellous bone in different bone sites in middle-aged female rats. Mech Ageing Dev 122:849-864

28. Ndiaye B, Cournot G, Pelissier MA, Debray OW, Lemonnier D 1995 Rat serum osteocalcin concentration is decreased by restriction of energy intake. J Nutr 125:1283-1290

28a. Egger CD, Muhlbauer RC, Felix R, Delmas PD, Marks SC, Fleisch H 1994 Evaluation of urinary pyridinium crosslink excretion as a marker of bone resorption in the rat. J Bone Miner Res 9:1211-1219

29. Kimmel DB 1994 In vivo animal models in osteoporosis research. In: Marcus R (ed) Osteoporosis. Blackwell Scientific Publications, Boston, pp 354-382

30. Kalu DN, Hardin RR, Cockerham R, Yu BP, Norling BK, Egan JW 1984 Lifelong food restriction prevents senile osteopenia and hyperparathyroidism in F344 rats. Mech Ageing Dev 26:103-112

31. Sato M, Vahle J, Schmidt A, Westmore M, Smith S, Rowley E, Ma LY 2002 Abnormal bone architecture and biomechanical properties with near-lifetime treatment of rats with PTH. Endocrinology 143:3230-3242 